\title{
Théologiques
}

Théologiques

\section{Dieu interdit}

\section{Olivette Genest}

Volume 6, numéro 2, octobre 1998

Dieu interdit

URI : https://id.erudit.org/iderudit/016655ar

DOI : https://doi.org/10.7202/016655ar

Aller au sommaire du numéro

Éditeur(s)

Faculté de théologie de l'Université de Montréal

ISSN

1188-7109 (imprimé)

1492-1413 (numérique)

Découvrir la revue

Citer ce document

Genest, O. (1998). Dieu interdit. Théologiques, 6(2), 3-6.

https://doi.org/10.7202/016655ar d'utilisation que vous pouvez consulter en ligne.

https://apropos.erudit.org/fr/usagers/politique-dutilisation/ 
LIMINAIRE

\section{Dieu interdit}

Olivette GENEST

Faculté de théologie

Université de Montréal

\section{Ante-scriptum}

Ce numéro ne vas pas sans clé de lecture, voire sans mode d'emploi. Il ne présente pas l'habituelle étude d'un thème, l'état de la recherche à son propos, un dossier bibliographique, des avancées à vérifier. Il propose le récit et le résultat d'un premier stade d'une expérience menée par le comité de rédaction de la revue, au niveau d'une question préalable non encore acquise. Il donne à voir des personnes réfléchissant à voix haute, à voix écrite, sur quelques perplexités facilement esquivées dans l'activité universitaire. C'est sur cette longueur d'onde que le numéro demande à être lu et il invite fortement au dialogue avec ses lecteurs et ses lectrices.

Sa genèse

Né des interrogations de Gilbert Renaud dans une réunion explo. ratrice sur de futurs thèmes, le "Dieu interdit " rencontra tant de connivences latentes, tacites ou explicites qu'on s'entendit très vite sur un processus d'élaboration inusité : le comité de rédaction serait lui-même le matériau et le maître d'œuvre du numéro. Nous n'allions pas nous répartir les différentes facettes d'un thème défini, mais construire ensemble un sujet dont nous n'avons pas encore tous les contours au moment d'aller sous presse. Nous le ferions à partir de nos ancrages disciplinaires respectifs, des positions personnelles adoptées, mais sans verser dans la confidence ni le témoignage, dans la liberté et l'autonomie complètes, avant de répondre - dans un autre numéro? - aux questions interdisciplinaires soulevées. 
Une telle décision nous engageait à nous exposer nous-mêmes, à nous compromettre en quittant la sécurité des réponses prêtes à consommer et signées de grands noms. Par goût du risque? Peut-être, car ce goût-là appartient à la recherche aux frontières de son propre champ du savoir, mais surtout, et ce qui appartient plus encore à la recherche, par envie d'entrer dans une réflexion véritable... avec ses risques. Nous produirions donc un numéro non pas sur Dieu, ni sur la manière de le dire ou de le taire, mais sur "l'état de la nation " dans chacune de nos disciplines quant à son effacement et à sa disparition des sciences humaines, y compris de la théologie. On constatera à la lecture que les frontières de ces consignes ont parfois été transgressées, au profit cependant de la richesse des articles.

Concrètement, affleurement et décantage collectifs des idées ont précédé l'élaboration de plans provisoires, suivie de la période d'écriture individuelle. Sur les premières versions, l'équipe entière s'est mise à agir comme son propre comité de lecture. Le plaisir de penser ensemble a de loin compensé les exigences de ces exercices. La rédaction des articles a produit cependant des réactions différentes. "Jamais plus de ma vie, je n'écrirai sur Dieu! ", a juré un des collègues hors théologie; les collègues de théologie souhaiteraient, eux, retrouver cette difficulté première sous le trop-plein de sources dont l'abondance désamorce les questions.

\section{Le résultat entre ces pages}

Par choix unanime, les articles déposés n'ont pas été harmonisés, ni remaniés de façon à répondre aux interrogations les uns des autres. Les approches restent disciplinaires, les niveaux d'écriture, la tonalité, le style, diversifiés. On y retrouve de tout: l'essai, l'évocation poétique, l'article documenté, la note personnelle, la touche impressionniste et même la liberté d'être conventionnel.

Un Québécois et sa "Révolution tranquille ", Gilbert Renaud, signe "une banale histoire de modernisation personnalisée " où Dieu "a été toujours davantage interdit et mis à mort ". Banalité et tranquillité aboutissent à sa présence incongrue à la revue Théologiques, secouent l'évolution récente du service social, mettent la théologie en demeure de clarifier son rapport à Dieu. Mêmes banalité et tranquillité sismiques chez Nicole Laurin, du point de vue de l'athéisme congénital de sa discipline. Le dieu que la socio- 
logie n'a pas aimerait ce regard incisif et rigoureux dirigé vers lui et la «logie » qui porte son nom.

De Dieu fait social, nous passons à Dieu instance et configuration discursives. Walter Moser met en scène une série de mutants discursifs divins et baisse le rideau sur le spectacle mythique d'un Dieu « véritable Protée post-moderne qui rejoue les fantasmes les plus anciens ", avec la virtuosité d'un maître de la métamorphose. Dans le texte biblique, par contre, Dieu règne-t-il enfin souverainement, sans travestis discursifs, tel qu'en lui-même la révélation nous l'aurait donné? Occupée d'un livre sur Dieu, dit de Dieu et plein de Dieu, l'exégèse parle-t-elle de Dieu à la bibliothèque, dans la salle de cours, dans les couloirs de l'université? Olivette Genest discute d'une omniprésence plus souvent absence et de la fluidité de cette contradiction aux allures de Protée.

Un autre lieu rempli de Dieu, celui du rituel, appelle aussi des nuances. On imagine mal Dieu refoulé à la porte de l'église, pour tant, Guy Lapointe défend la liturgie d'être mainmise et consommation de son principal acteur. Il la montre comme espace symbolique, ouvert pour son passage, dans l'entrelacs du soi, de l'autre et de l'Autre. Jean-Guy Nadeau, pour sa part, fait courageusement œuvre théorique en théologie pratique, à la recherche de sa définition et de la part qu'elle fait à Dieu. "La perplexité d'un constructiviste nos talgique " qu'il s'attribue ne nous étonne plus, après qu'il nous ait menés systématiquement entre théologies pratiques, empiriques, critiques, fondamentales et pastorales, et gratifiés d'un précieux dossier de références pour la suite du périple.

Puis, "Un son de fin silence ». Une incursion chez les mystiques, toute de saveur et de sagesse, débouche, pour Jean-Claude Petit, sur la réclamation d'une véritable question sur Dieu en théologie, c'est-àdire une quaestio, une quête plutôt qu'une accumulation de savoirs, qui équivaut à un encombrement de réponses. Denise Couture s'est chargée de l'importante lecture transversale de ces sept contributions. Tissu de connivences, de heurts, de surprises? Apparition de quel type de problématique et de ce qu'il faudrait mettre en action pour l'articuler correctement? Projets subséquents? Ensemble ouvert sur sa propre suite.

Le point d'arrivée s'est mué en point de départ. Après la peine, et surtout le plaisir, de l'élaboration de ce numéro, qu'en est-il du Dieu 
interdit? Et du Dieu inter-dit de l'interdisciplinarité? De l'angle qui est le sien, Nicole Laurin conclut: la sociologie "peut seulement espérer que la théologie pose son regard sur la société, et que ce regard puisse croiser celui de la science, au-delà du fossé épistémologique séparant ces deux domaines de la pensée. Si toutefois la place du discours sur Dieu est vide, en théologie comme en science, il n'y aura plus alors qu'à s'en remettre au silence ", à un silence qui n'est pas celui des mystiques, on le devine, mais qui parle d'une lucidité qui ne demande qu'à se dire.

Olivette GENEST et Gilbert RENAUD, responsables de ce numéro 